\title{
NASA-Langley Web-Based Operational Real-time Cloud Retrieval Products from Geostationary Satellites
}

\author{
Rabindra Palikonda*a, P. Minnis $^{\mathrm{b}}$, D. A. Spangenberg ${ }^{\mathrm{a}}$, M. M. Khaiyer ${ }^{\mathrm{a}}$, M. L. Nordeen ${ }^{\mathrm{a}}$, J. K. \\ Ayers $^{\mathrm{a}}$, L. Nguyen ${ }^{\mathrm{b}}$, Y. Yi ${ }^{\mathrm{a}}$, P. K. Chan ${ }^{\mathrm{a}}$, Q. Z. Trepte ${ }^{\mathrm{c}}$, F.-L. Chang ${ }^{\mathrm{d}}$, W. L. Smith, Jr. ${ }^{\mathrm{b}}$ \\ ${ }^{a}$ Analytical Services \& Materials Inc., Hampton, VA \\ ${ }^{\mathrm{b}}$ Climate Science Branch, NASA-Langley Research Center, Hampton, VA \\ ${ }^{\mathrm{c}}$ Science Applications International Corporation, Hampton, VA \\ ${ }^{\mathrm{d}}$ National Institute of Aerospace, Hampton, VA
}

\begin{abstract}
At NASA Langley Research Center (LaRC), radiances from multiple satellites are analyzed in near real-time to produce cloud products over many regions on the globe. These data are valuable for many applications such as diagnosing aircraft icing conditions and model validation and assimilation. This paper presents an overview of the multiple products available, summarizes the content of the online database, and details web-based satellite browsers and tools to access satellite imagery and products.
\end{abstract}

Keywords: VISST, cloud microphysical properties, GOES, MTSAT-1R, FY2-C

\section{INTRODUCTION}

Ground-based instruments measuring cloud and radiative parameters can monitor the atmospheric state above a given site, but cover very little of the Earth's surface. Satellite imager data can be used to retrieve a variety of cloud and radiative parameters over large-scale regions. With validation from ground-based instrumentation, satellite-derived datasets can be a valuable asset in climatic studies and complement the surface-based measurements. The LaRC cloud products algorithm combines the Visible Infrared Solar-Infrared Split-Window Technique (VISST, Solar-infrared Infrared Split-window Technique (SIST), and Solar-infrared Infrared Near-infrared Technique (SINT) ${ }^{7,8}$. For convenience, the three algorithms are referred to collectively as VISST. The availability of additional satellite spectral channels, combined with advances in our understanding of clouds and their interaction with the atmosphere, led to the development of an improved algorithm. In addition to the VIS $(0.65 \mu \mathrm{m})$ and IR $(10.8 \mu \mathrm{m})$ channels, VISST employs as many as three additional channels; $1.6,3.9$, and 12 or $13.3 \mu \mathrm{m}$, depending on the application and availability, resulting in improved retrieval accuracies. These near-real time datasets can be used for estimating surface atmospheric radiation budgets $^{5}$, numerical weather prediction, validation and assimilation and a variety of nowcasting applications ${ }^{4,10}$.

\section{METHODOLOGY, DATA \& DOMAIN}

\subsection{Methodology:}

VISST is a 4-channel model-matching method that assumes plane parallel clouds. It matches observed radiances to theoretical model calculations for 7-water and 9-ice crystal size distribution. Satellite radiances, at near real-time, are analyzed to derive cloud properties at high temporal and spatial resolutions. Additional required inputs include temperature and humidity profiles from NOAA Rapid Update Cycle (RUC) or Global Forecast System (GFS) forecasts for estimations of skin temperature, cloud height and radiance attenuation calculations. Surface-type definition is based on the International Geosphere-Biosphere Program (IGBP) surface map; spatial distributions of snow/ice are taken from real-time maps generated by the NOAA/NESDIS Interactive Multisensor Snow and Ice Mapping System (IMS); and clear-sky reflectance data from the Clouds and Earth's Radiant Enery System (CERES) are used to provide background radiances for cloud detection and retrieval ${ }^{2}$. Narrowband-to-broadband flux conversion coefficients developed from

*r.palikonda@larc.nasa.gov; phone 1-757-8274664; www-pm.larc.nasa.gov 
Table 1. Domains and available products from NASA LaRC

\begin{tabular}{|c|c|c|c|}
\hline \multirow[t]{2}{*}{ DOMAIN } & \multirow[t]{2}{*}{ COVERAGE } & \multicolumn{2}{|l|}{ PRODUCTS } \\
\hline & & VISST & GIF IMAGERY \\
\hline EAST CONUS: (Half Hourly) & $55 \mathrm{~N}-18 \mathrm{~N}, 105 \mathrm{~W}-60 \mathrm{~W}$ & & \\
\hline GOES EAST (8km): & & Oct. 2003 - Present & Oct. 2003 - Present \\
\hline WEST CONUS: (Half Hourly) & $55 \mathrm{~N}-18 \mathrm{~N}, 130 \mathrm{~W}-90 \mathrm{~W}$ & & \\
\hline GOES WEST (8km): & & Oct. 2003 - Present & Oct. 2003 - Present \\
\hline MERGED CONUS : & $55 \mathrm{~N}-18 \mathrm{~N}, 130 \mathrm{~W}-60 \mathrm{~W}$ & & \\
\hline GOES EAST\& WEST $(8 \mathrm{~km}):$ & & Oct. 2003 - Present & Oct 2003 - Present \\
\hline WESTERN EUROPE: (Hourly) & $54 \mathrm{~N}-39 \mathrm{~N}, 4 \mathrm{~W}-17 \mathrm{E}$ & & \\
\hline MSG $(3 \mathrm{~km})$ : & & Apr 2005 - Present & Apr 2005 - Present \\
\hline EUROPE: (Hourly) & $55 \mathrm{~N}-30 \mathrm{~N}, 12 \mathrm{~W}-30 \mathrm{E}$ & & \\
\hline MSG $(6 \mathrm{~km}):$ & & May 2004 - Present & May 2004 - Present \\
\hline North Slope Alaska (NSA) & $74 \mathrm{~N}-64 \mathrm{~N}, 165 \mathrm{~W}-140 \mathrm{~W}$ & & \\
\hline GOES-WEST, & & Oct. 2005 - Present & Oct. 2005 - Present \\
\hline AVHRR & & Oct 2005 - Present & Oct 2005 - Present \\
\hline Southern Great Plains: & $42 \mathrm{~N}-32 \mathrm{~N}, 105 \mathrm{~W}-91 \mathrm{~W}$ & & \\
\hline GOES EAST \& WEST $(4 \mathrm{~km})$ & & Jan. 1998 - Present & Jan.1996-Present \\
\hline Tropical Western Pacific: & $10 \mathrm{~N}-20 \mathrm{~S}, 120 \mathrm{E}-180 \mathrm{E}$ & & \\
\hline GOES-9 $(8 \mathrm{~km})$ & & May 2003 - Nov 2005 & May 2003 - Nov 2005 \\
\hline MTSAT-1R (4 km) & & Jan, 2006 - Present & Jan 2006 - Nov 2005 \\
\hline Manus: (Hourly) & $3 \mathrm{~N}-12 \mathrm{~S}, 135 \mathrm{E}-160 \mathrm{E}$ & & \\
\hline GOES-9 (4 km) & & May 2003 - Nov 2005 & May 2003 - Nov 2005 \\
\hline MTSAT-1R (4 km) & & Jan, 2006 - Present & Jan, 2006 - Present \\
\hline Nauru: (Hourly) & $3 \mathrm{~N}-17 \mathrm{~S}, 155 \mathrm{E}-180 \mathrm{E}$ & & \\
\hline GOES-9 (4 km) & & May 2003 - Nov 2005 & Jan. 2005 - Nov 2005 \\
\hline MTSAT-1R (4 km) & & Jan, 2006 - Present & Jan, 2006 - Present \\
\hline Darwin: (Hourly) & $5 \mathrm{~S}-17 \mathrm{~S}, 125 \mathrm{E}-136 \mathrm{E}$ & & \\
\hline GOES-9 (4 km) & & May 2003 - Nov 2005 & Jan. 2005 - Nov 2005 \\
\hline MTSAT-1R (4 km) & & Jan, 2006 - Present & Jan, 2006 - Present \\
\hline FY-2C (4 km) & & Jan, 2006 & Jan. 2006 \\
\hline
\end{tabular}

correlations of coincident CERES broadband and GOES narrowband fluxes are used to compute broadband shortwave and longwave fluxes. Comparisons of VISST-derived cloud properties with aircraft in-situ measurements and groundbased instruments have been very favorable $e^{3,6}$. The algorithms are often improved as our knowledge base increases. Calibrations are updated to account for satellite instrument degradation ${ }^{9}$. For this reason, more recent cloud products tend to be more accurate than from earlier periods. VISST products during field experiments are updated with latest version of the algorithm.

\subsection{Data and Domain:}

As part of the Atmospheric Radiation Measurement Program (ARM), LaRC has been providing Geostationary Operational Environmental Satellite (GOES) satellite-derived cloud and radiation datasets for more than 10 years. This effort was recently expanded to cover the entire continental United States (CONUS) in early 2004 using data from GOES-10 \& GOES-12 and, later, GOES-11 to facilitate real-time diagnosis of aircraft icing conditions ${ }^{10}$. Since then retrievals have been implemented over Europe and Africa from Meteosat Second Generation (MSG or Meteosat-8) satellite, the Pacific Ocean and Australia from the Multi-functional Transport Satellite (MTSAT-1R) and Asia from Feng-Yun-2 (FY2C). The domain definitions and temporal resolutions for each domain are listed in Table 1. 

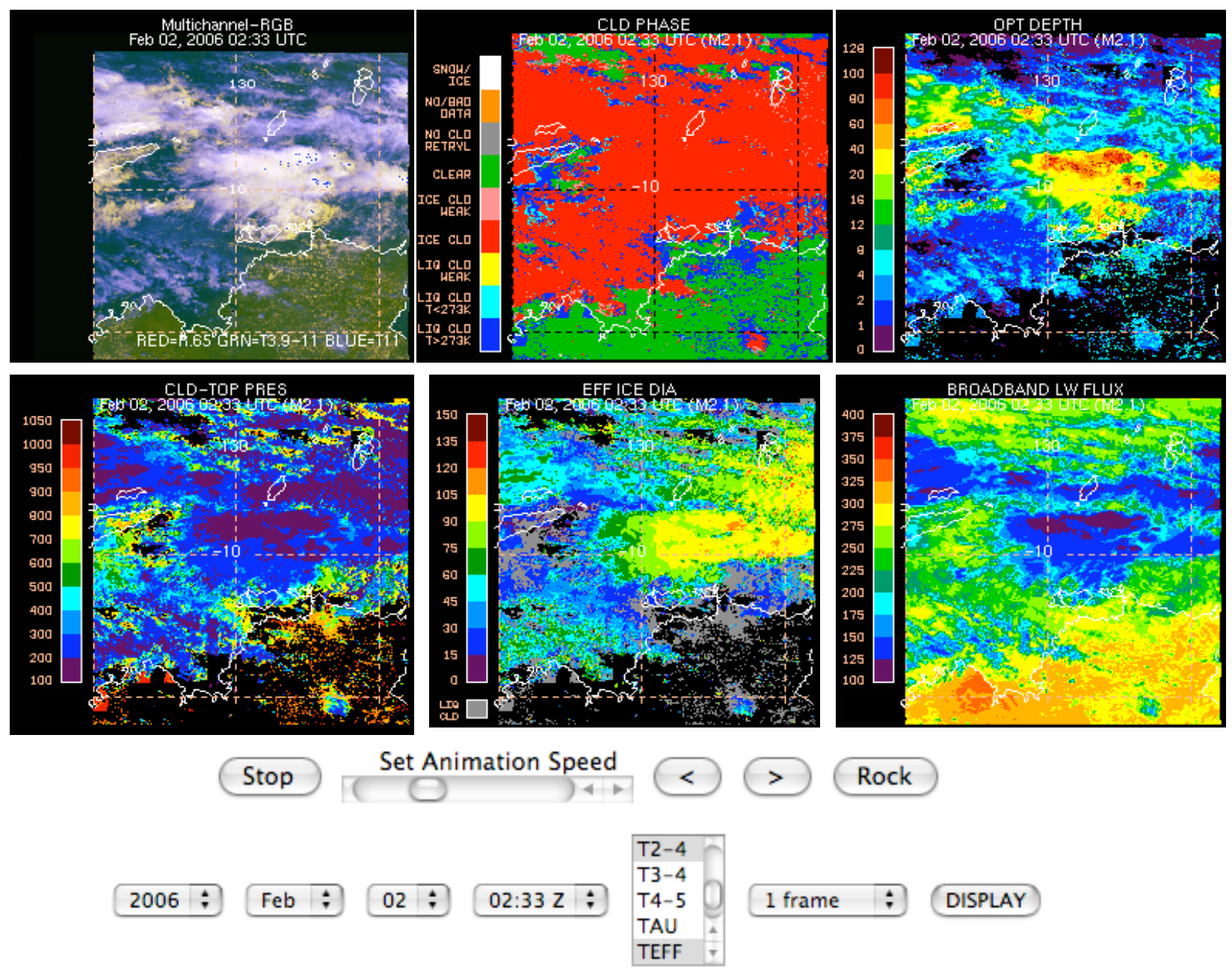

Fig. 1. VISST cloud products from MTSAT-1R during TWPICE, 02:33 UTC, 2 Feb 2006. Buttons at bottom show the types of menus available for displaying the products.

\section{PRODUCTS, DATA ACCESS AND WEB TOOLS}

\subsection{Near Real Time Products:}

Hourly spectral data from the satellites in Table 1. are analyzed to generate a set of products (Fig 1). These results become available online within a couple of hours after the image time. Over CONUS, each half-hourly GOES-WEST and GOES-EAST satellite data is analyzed to generate cloud products. The individual product images from each satellite are merged together to give a real-time product over CONUS. The data are merged at $100^{\circ} \mathrm{W}$ longitude. As described earlier ${ }^{11}$, three type of cloud products are available.

\subsection{Pixel Level}

Pixel-level products are retrieved at the instrument pixel resolution. Certain large domains (CONUS 8km, EUROPE $6 \mathrm{~km}$, TWP $8 \mathrm{~km}$ ) are analyzed at lower resolution to keep the required computer resources at a manageable level and to output the products in a timely fashion. For lower resolution analyses, the processing skips the requisite number of lines and pixels to achieve the specified resolution. The efficiency of the software is being enhanced with the goal to process these domains at the higher resolution with faster turnaround. Each pixel is classified as clear or cloudy. Clear 
Table 2. VISST pixel-level cloud products.

\section{Current Products}

$0.65 \mu \mathrm{m}$ Reflectance

12 or $13.3-\mu \mathrm{m}$ Temp

Eff Radius/Diameter

Broadband SW Albedo

Infrared Emittance

Cloud Phase

\section{New products:}

Surface Flux:
$3.7 \mu \mathrm{m}$ Temperature

$1.6 \mu \mathrm{m}$ Reflectance

Liquid/Ice Water Path

Broadband LW Flux

Cloud Top Height

Cloud Bottom Height

\section{$6.7 \mu \mathrm{m}$ Temperature $\quad 10.8 \mu \mathrm{m}$ Temperature \\ Skin Temperature}

Cloud Effective Temp

Cloud Top Pressure

Cloud Eff Pressure

Cloud Bottom Pressure

Cloud Mask

Cloud Effective Height

pixels are denoted as clear or snow. Each cloudy pixel is assigned a phase (water, super-cooled water, or ice) and cloud microphysical and radiative properties are derived from the pixel radiances using VISST. Table 2 . summarizes the VISST pixel-level products. A multi-layer cloud identification algorithm ${ }^{1}$ will soon be integrated into the real-time processing. Fig 2. shows an example from GOES-12 of both the current single layer cloud mask from VISST and the multi-layered cloud mask. The magenta and yellow colored pixels are the multi-layered pixels. When this is operational, every cloudy pixel is identified as either single or multi-layer. The multi-layer pixel will further have both low and high cloud properties derived. The increased retrieval accuracy will enhance the utility of the results for many value added products.

\subsection{Gridded Products}

Gridded cloud products are calculated on a user-defined resolution (e.g. $0.5^{\circ}$ x $0.5^{\circ}$ ). The individual pixels within each grid box are averaged based on cloud height or phase to provide an average value for each grid. Each cloud property listed in Table 2 can be averaged by cloud height (low, mid, high, total) or by phase. Recently, up- and downwelling surface longwave and shortwave fluxes have been added to the gridded product set. Top-of atmosphere albedos and
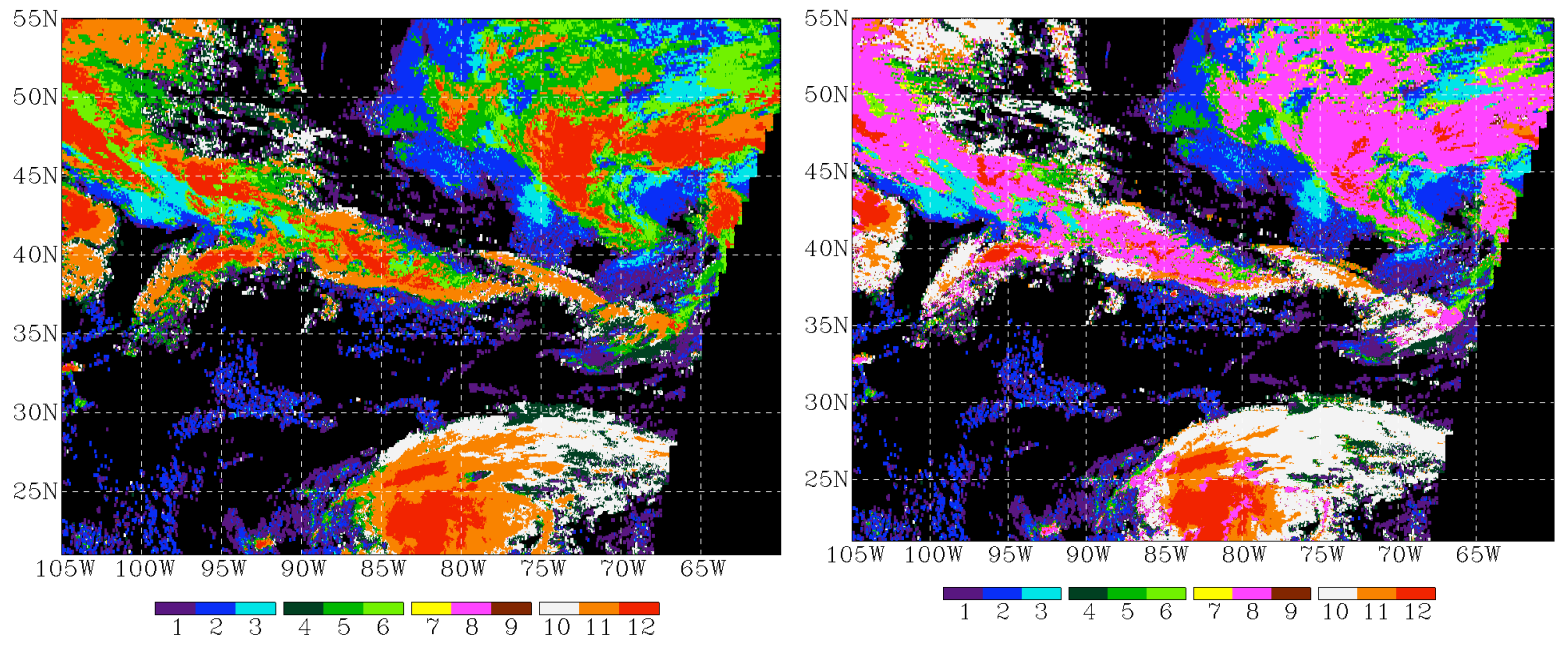

Fig 2: Single layer cloud mask from VISST on the right and Multi - layered mask on the right from GOES-12, June 10, 2006 at 17:15 UTC. 1: Single low cloud (Tau <3.6) 2: Single low cloud (Tau =3.6-23) 3: Single low cloud (Tau > 23)4: Single mid cloud (Tau <3.6) 5: Single mid cloud (Tau=3.6-23) 6: Single mid cloud (Tau > 23)7: Multi-layer $(\mathrm{Pc} 1=440-500 \mathrm{mb})$ 8: Multi-layer (upper layer Pc1 < 440mb) 9: Marginal multi-layer (lower-layer Tau2 is small <1.5) 10: Single thin cirrus cloud (Tau <3.6) 11: Optical-thick high cloud (Tau = 3.6-23) 12: Optical-thick-high cloud (Tau $>23$ ) 


\section{TWP MTSAT-1R OCT 18, $2006 \quad 23: 332$ \\ VISST DERIVED $0.5 \times 0.5^{\circ} \mathrm{GRIDDED}$ \\ TOTAL CLOUD PERCENTAGE}

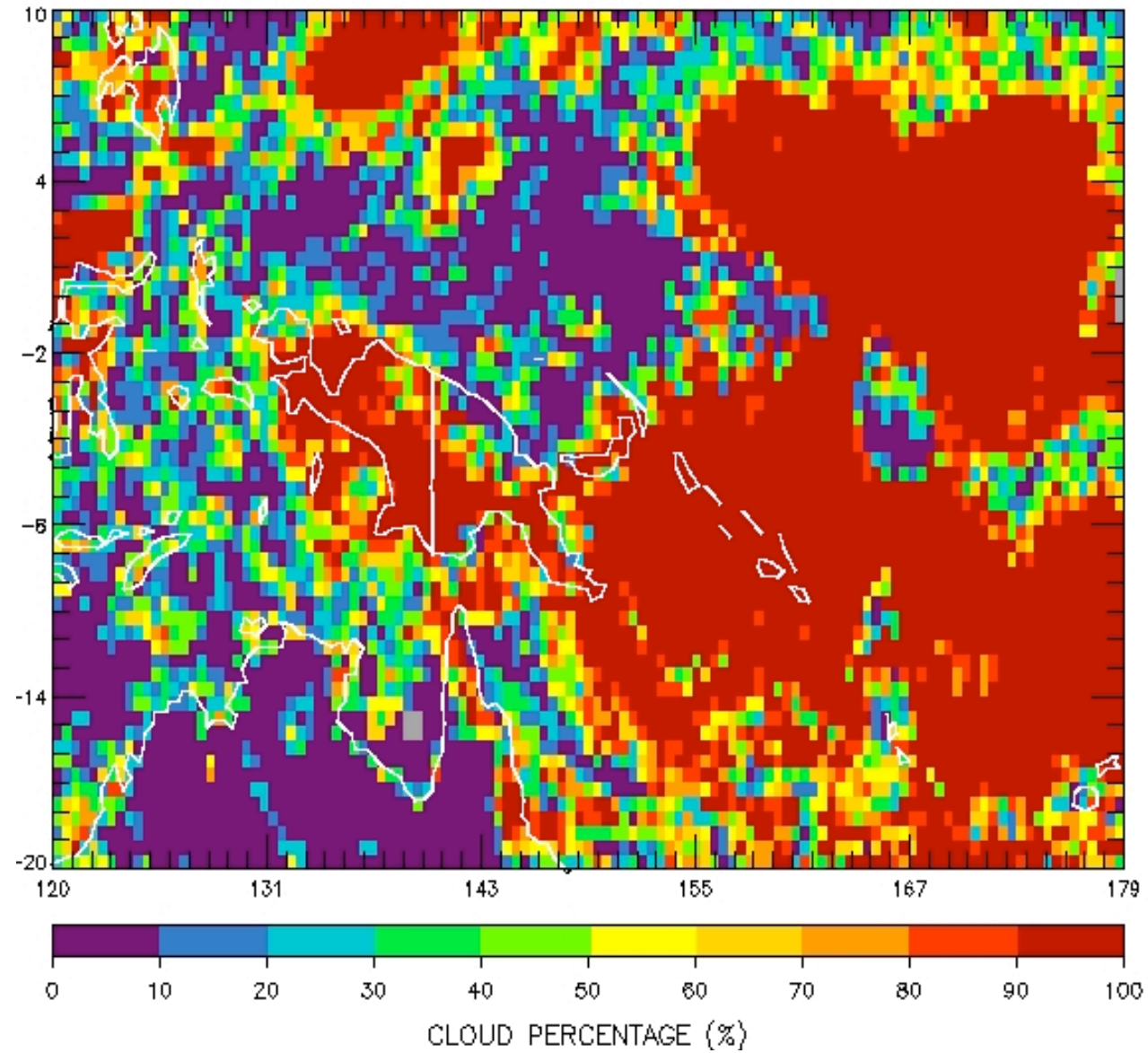

\begin{tabular}{|c|c|c|c|c|}
\hline TWP $\quad \vdots$ & Cloud per & \% & Total Cloud & $\vdots$ \\
\hline $2006 \div$ & Oct $:$ & $18 \div$ & From: $23: 00 \mathrm{z}$ & To: $23: 00 \mathrm{Z}$ \\
\hline \multicolumn{5}{|c|}{ DISPLAY } \\
\hline
\end{tabular}

Fig. 2. Gridded VISST product: Total cloud \% over the Tropical Western Pacific Domain from MTSAT-1R.

outgoing longwave radiation are combined with the VISST cloud products to derive the surface fluxes at the grid scale ${ }^{5}$. An example of the gridded products is given in Fig 2. that shows the total cloud cover over the Tropical Western Pacific (TWP) at 2333 UTC, 16 October 2006 averaged on a $0.5^{\circ}$ grid. Little cloud cover is seen over Australia, while the island of New Guinea and areas to the east are mostly overcast. These gridded products greatly reduce the volume of data but suffer some loss of detail compared to the pixel level products (Fig. 1).

\subsection{Surface-Site \& Field Experiment Products}

To support various field experiments and Intensive Observation Periods (IOP), comprehensive satellite, model, and meteorological data web sites were developed and used extensively during the planning and execution of the field 

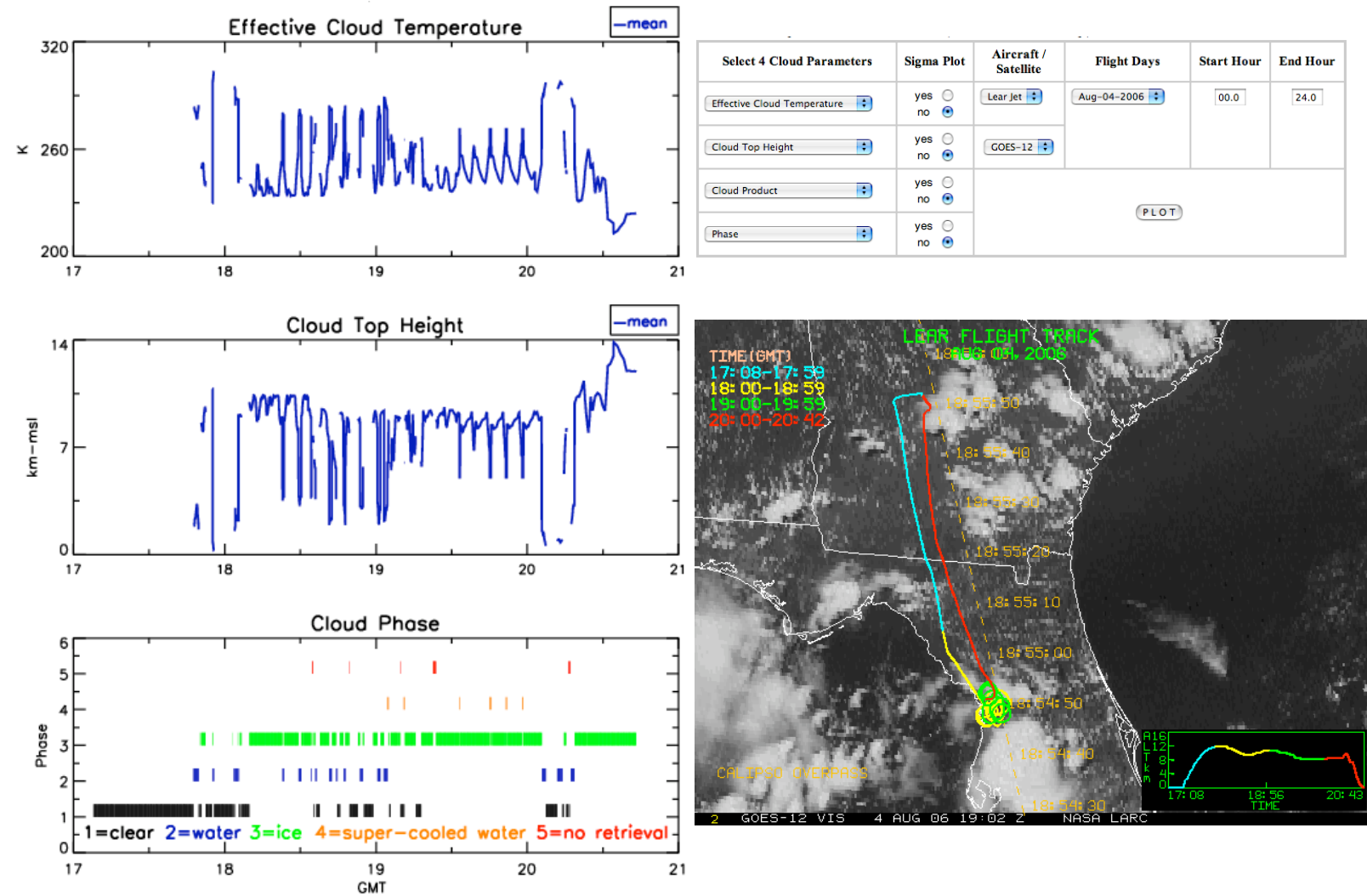

Fig. 4. Online tool (upper right) to plot VISST products (left) along the Learjet flight track during CALIPSO-CloudSat Validation Experiment (CCVEX) experiment, 4 August 2006. TheGOES-12 image at lower right is shown overlaid with the aircraft flight track and CALIPSO satellite overpass. The plot in the lower right of the image shows the altitude of the Learjet.

experiments. Table 3. lists some recent field experiments supported by the LaRC satellite group. The surface site datasets consist of pixel-level quantities averaged within a 10 or $20-\mathrm{km}$ radius circle of a particular surface site (ARM sites: SGP CF, Barrow, Nauru, Manus and Darwin, European sites: SIRTA, Chilbolton, Cabauw, Lindenberg \& Potenza). During the field experiments, cloud products are available at higher temporal resolutions (every 5 - 30 minutes depending on availability) from the geostationary satellites (e.g. GOES, Meteosat-8, MTSAT-1R) and from all available overpasses from Sun-synchronous satellites (e.g. AVHRR, MODIS). The aircraft-matched VISST products are calculated from the individual aircraft navigation files, where the cloud retrieval parameter is based on the weighted average of the four closest satellite pixels nearest to the aircraft coordinates. The spatial standard deviation for each parameter is calculated using a weighted distribution of the values from the closest pixel and its eight closest neighbors.

Fig. 4 shows an example of a few of the products made available during and after field experiments. The flight tracks of the research Learjet are overlaid on a GOES-12 visible image taken at the center time of the flight conducted 4 August 2006 during the CALIPSO-CloudSat Validation Experiment (CCVEX). This type of plot summarizes the entire flight. Individual legs of each flight are also plotted on the geostationary satellite image taken closest in time to the leg, so that the flight path can be animated, and the satellite and aircraft measurements can be matched as closely as possible. The cloud-radiation parameters are averaged along the flight path as described above and stored online for selection and plotting via the interactive menu shown in the upper right portion of Fig. 4. Values for 3 different VISST parameters corresponding to the Learjet flight path are plotted in the left half of the figure. In addition to plots, the selected data are also provided in text format for downloading. Similar tools are available for selecting data over the instrumented surface sites. A variety of other products and tools are also available for a variety of purposes. One of the most widely used tools is the satellite orbit predictor that is used to provide information about future and past overpass times, and viewing and illumination angles for many different satellites. 
Table 3. Internet links to recent LaRC supported field experiment web sites.

\begin{tabular}{|c|c|}
\hline FIELD EXPERIMENT & DEDICATED WEBSITE \\
\hline $\begin{array}{l}\text { CALIPSO \& CloudSat Validation Experiment } \\
\text { (CCVEX) }\end{array}$ & http://angler.larc.nasa.gov/ccvex \\
\hline $\begin{array}{l}\text { Tropical Warm Pool International Cloud Experiment } \\
\text { (TWP-ICE) }\end{array}$ & $\underline{\text { http://angler.larc.nasa.gov/twpice }}$ \\
\hline $\begin{array}{c}\text { The Cirrus Regional Study of Tropical Anvils and } \\
\text { Cirrus Layers - Florida Area Cirrus Experiment } \\
\text { CRYSTAL }\end{array}$ & $\underline{\text { http://angler.larc.nasa.gov/crystal }}$ \\
\hline $\begin{array}{c}\text { Atlantic THORpex Regional Campaign Alliance } \\
\text { Icing Research Study II (ATREC) }\end{array}$ & $\underline{\text { http://angler.larc.nasa.gov/bangor }}$ \\
\hline Middle Latitude Cirrus Experiment (MIDCIX) & $\underline{\text { http://angler.larc.nasa.gov/midcix }}$ \\
\hline $\begin{array}{l}\text { MPACE Mixed-Phase Arctic Cloud Experiment } \\
\text { (MPACE) }\end{array}$ & http://angler.larc.nasa.gov/mpace \\
\hline $\begin{array}{c}\text { THORPEX } 2003 \text { Pacific THORPEX Observing } \\
\text { System Test }\end{array}$ & http://angler.larc.nasa.gov/thorpex \\
\hline ARM- South Great Plains & http://angler.larc.nasa.gov/armsgp \\
\hline
\end{tabular}

\subsection{Online datasets \& web-tools:}

LaRC maintains an online database and website at http://www-pm.larc.nasa.gov/satimage/products.html to access near real-time or archived VISST results and satellite imagery. The database includes a multi-year time series of site-specific averages including more than 100 cloud and radiative parameters, pixel-level gif images of retrieved properties, and binary pixel-level retrievals for selected regions. This site has web-based satellite data browsers and tools to access satellite imagery. These images are in GIF format and can be downloaded to local computer systems. From the pixellevel dataset, the user has options to select the domain, single or multi-panel images, and time series to view an animation of the products (Fig. 1). A similar tool is available to select a domain and view animation of the gridded VISST products (Fig. 2). The user can also download the gridded product in netcdf format. Another tool helps retrieve data or plot cloud products over the surface sites or along flight tracks during the IOP's (Fig. 4). The user can choose up to four cloud products at a time along with the cloud phase and radius (10 or $20 \mathrm{~km})$. The plots are generated in both GIF and postscript format. A link to access the ASCII data is also provided. Users can download the ASCII data and integrate them into their application. Dedicated websites for each IOP have links to these additional datasets and tools (Table 3).

\section{SUMMARY}

A large array of cloud and radiation products has been developed from a variety of satellite imager radiances. The products are available online. As improvements in algorithms, such as multilayered cloud detection, and calibrations become available, they will be implemented and used to update the older results. Several tools have been developed to provide easy access to the data. New tools for enhanced accessibility are under development and will be placed online when they become available. These products are derived for use by the atmospheric science community and by the public at large. Any comments, suggestions, or other feedback are welcomed.

\section{ACKNOWLEDGMENTS}

This research is supported by the Office of Biological and Environmental Research of U.S. Department of Energy through the Pacific Northwest National Laboratory ITF 3407 as part of the Atmospheric Radiation Measurement Program and by the NASA Aviatio Safety Program through the Advanced Satellite Aviation-weather Products Initiative. 


\section{REFERENCES}

1. Chang, F.-L., and Z. Li, A new method for detection of cirrus overlapping water clouds and determination of their optical properties. J. Atmos. Sci., 62, 3993-4009, 2005.

2. Chen, Y., S. Sun-Mack, P. Minnis, and R. F. Arduini, Clear-sky narrowband albedo variations derived from VIRS and MODIS data. Proc. AMS 12th Conf. Atmos. Radiation, Madison, WI, July 10-14, CD-ROM, 5.6, 2006.

3. Dong, X., P. Minnis, G. G. Mace, W. L. Smith, Jr., M. Poellot, R. T. Marchand, and A. D. Rapp, Comparison of stratus cloud properties deduced from surface, GOES, and aircraft data during the March 2000 ARM Cloud IOP. $J$. Atmos. Sci., 59, 3256-3284, 2002.

4. Haggerty, J., G. Cunning, B. Bernstein, P. Minnis, and R. Palikonda, Integration of advanced satellite products into an icing nowcast system. Proc. WWRP Symp. Nowcasting \& Very Short Range Forecasting, Toulouse, France, 5-9 September, CD-ROM, 4.14, 2005.

5. Khaiyer, M. M., D. R. Doelling, P. K. Chan, M. L. Nordeen, R. Palikonda, and Y. Yi, Derivation of improved surface and TOA broadband fluxes using CERES-derived narrowband-to-broadband coefficients. Proc. AMS 12th Conf. Atmos. Radiation, Madison, WI, July 10-14, CD-ROM, P3.5, 2006.

6. Mace, G. G., Y. Zhang, S. Platnick, M. D. King, P. Minnis, and P. Yang, Evaluation of cirrus cloud properties from MODIS radiances using cloud properties derived from ground-based data collected at the ARM SGP site. J. Appl. Meteorol., 44, 221-240, 2005.

7. Minnis, P., D. P. Kratz, J. A. Coakley, Jr., M. D. King, D. Garber, P. Heck, S. Mayor, D. F. Young, and R. Arduini, Cloud Optical Property Retrieval (Subsystem 4.3), Clouds and the Earth's Radiant Energy System (CERES) Algorithm Theoretical Basis Document, Volume III: Cloud Analyses and Radiance Inversions (Subsystem 4). NASA RP 1376 Vol. 3, edited by CERES Science Team, pp. 135-176, 1995.

8. Minnis, P., D. P. Garber, D. F. Young, R. F. Arduini, and Y. Takano, Parameterization of reflectance and effective emittance for satellite remote sensing of cloud properties. J. Atmos. Sci., 55, 3313-3339, 1998.

9. Minnis, P., L. Nguyen, D. R. Doelling, D. F. Young, W. F. Miller, and D. P. Kratz, Rapid calibration of operational and research meteorological satellite imagers, Part I: Evaluation of research satellite visible channels as references. $J$. Atmos. Oceanic Technol., 19, 1233-1249, 2002.

10. Minnis, P., L. Nguyen, W. L. Smith, Jr., J. J. Murray, R. Palikonda, M. M. Khaiyer, D. A. Spangenberg, P. W. Heck, and Q. Z. Trepte, Near real-time satellite cloud products for nowcasting applications. Proc. WWRP Symp. Nowcasting \& Very Short Range Forecasting, Toulouse, France, 5-9 September, CD-ROM 4.19, 2005.

11. Palikonda, R., D. Phan, M. M. Khaiyer, M. L. Nordeen, J. K. Ayers, D. A. Spangenberg, D. R. Doelling, Y. Yi, P. Minnis, L. Nguyen, Q. Trepte, and S. Sun-Mack, NASA-Langley web-based operational real-time cloud retireval products from geostationary satellties. Proc. AMS 14th Conf. Satellite Meteorol. and Oceanog., Atlanta, GA, 29 Jan. - 2 Feb. 2006, CD-ROM, P4.18, 2006. 